\title{
A Puzzle about Imagining Believing
}

\author{
Alon Chasid \\ Bar-Ilan University \\ [Penultimate version; forthcoming in Review of Philosophy and Psychology]

\begin{abstract}
Suppose you're imagining that it's raining hard. You then proceed to imagine, as part of the same imaginative project, that you believe that it isn't raining. Such an imaginative project is possible if the two imaginings arise in succession. But what about simultaneously imagining that it's raining and that you believe that it isn't raining? I will argue that, under certain conditions, such an imagining is impossible. After discussing these conditions, I will suggest an explanation of this impossibility. Elaborating on the view outlined in Walton (1990), I will argue that the impossibility follows from the fact that imaginings 'mimic' beliefs in aiming at the fictionally true, just as beliefs aim at the true.
\end{abstract}

Keywords: imaginings; belief-like imagining; make-believe; belief; propositional attitudes; Moore's paradox; Kendall Walton

\section{Preliminaries}


The term 'imagining' and its cognates can denote several different kinds of mental states, e.g., false beliefs, mental imagery, mere thoughts, etc. (see, e.g., Kind 2013; 2016, 2ff; Van Leeuwen 2013). In this paper, 'imagining' denotes belief-like imagining. ${ }^{1}$ Belief-like imaginings are representational states with propositional content; they may arise in pretending, playing games of make-believe, daydreaming, mindreading, modal reasoning, responding to reading or watching fiction, and so on. They may also arise, spontaneously or intentionally, without any connection to these settings. It is widely accepted that such imaginings are functionally similar to beliefs: they are related to other kinds of mental states - conative states, emotional responses, motivations - in a manner akin to that in which beliefs are related to those states or similar ones. ${ }^{2}$ It is also widely accepted that belief-like imaginings mirror the inferential patterns of beliefs, i.e., that the same inferential mechanism that governs beliefs also applies to imaginings. ${ }^{3}$ The differences

\footnotetext{
${ }^{1}$ Although belief-like imaginings are sometimes called 'propositional' or 'attitudinal' imaginings, using these terms here could be misleading, since desire-like imaginings and sensory (perception-like) imaginings can also be deemed propositional or attitudinal; see Kind (2013, 154-155); (2016, 5-6).

${ }^{2}$ See, e.g., Arcangeli (2019b), Currie and Ravenscroft (2002), Doggett and Egan (2007; 2012), Gendler (2003), Ichino (2019), Kind (2013), Langland-Hassan (2012), Liao and Doggett (2014), Liao and Gendler (2020), Nichols (2004; 2006), Nichols and Stich (2003), Van Leeuwen (2011; 2013), Walton (1990; 2015).

${ }^{3}$ See, e.g., Currie and Ravenscroft (2002), 12ff; Nichols (2006), §3.5; Weinberg and Meskin (2006), 180-181; Van Leeuwen (2013); Stock (2017), §6.2. Another, less
} 
between belief-like imaginings and beliefs ensue from the fact that whereas beliefs aim at truth simpliciter, and hence are responsive to evidence, consistent with other beliefs about the real world, etc., imaginings do not: imaginings do not respond to evidence, need not be consistent with beliefs about the real world, etc. (Kind 2016, 3ff).

The fact that imaginings do not aim at truth does not mean that they are totally unconstrained. For instance, although we can consider, assume, hypothesize, entertain in thought, etc., an overt logical contradiction (e.g., ' $p$ and not- $p$ '), most philosophers deny that we can imagine such a contradiction. ${ }^{4}$ Similarly, on certain views, it is impossible to discussed, similarity between imaginings and beliefs is that imaginings 'aim' at the fictional just as beliefs aim at the true (Walton 1990; see $\S 4$ below).

${ }^{4}$ That we cannot imagine an overt contradiction is usually accepted not only by those who take imagining to have an 'imagistic' or sensory component, but also by those who deny this; see Kind $(2013,151)$. Note too that I did not list the attitude of supposing, which on certain views (e.g., Currie and Ravenscroft 2002; cf. Balcerak Jackson 2016; Arcangeli 2019a) is regarded as (a type of) belief-like imagining. For if supposing is (a type of) belief-like imagining, the scope of belief-like imagining to which the puzzle in question applies should be narrowed, since without further qualification, we can suppose an overt logical contradiction (e.g., in reductio ad absurdum), and a fortiori, we can suppose content such as Moorean conjunctions. To be compatible with these views, my argument should be taken to apply only to imaginings that are constrained in certain ways, ways that render them subject to the puzzle (see my explanation below). Accordingly, my solution to the puzzle should be seen as revealing the specific constraints that render imagining subject to the puzzle. 
imagine, as per the puzzle of imaginative resistance, morally-deviant propositions (Tuna 2020). There may also be specific constraints on imagining; e.g., if one is engaged in an imaginative project ${ }^{5}$ in which the next-door neighbor is taken to be a dragon, one is 'committed' to responding to any sighting of that neighbor by imagining that there is a dragon there. However, despite such constraints and others, there is a significant difference between beliefs and belief-like imaginings: beliefs track truth simpliciter, whereas imaginings do not.

Belief-like imaginings differ from the sensory or 'imagistic' imaginings that sometimes, perhaps always, accompany them. ${ }^{6}$ Sensory imaginings are not belief-like, but rather are akin to perceptual experiences. I do not deny that sensory imaginings play a role in imaginative projects, but my argument applies to belief-like imaginings. My argument is also compatible with views on which states such as imagining experiencing (e.g., imagining seeing a tree), imagining doing something (e.g., imagining playing the

${ }^{5}$ I will take an imaginative project to be the overall mental activity associated with imagining. More precisely, an imaginative project encompasses implicit and explicit imaginings, stipulations regarding the fictional world at which one's imaginings are directed, patterns of inference that apply to one's imaginings, various kinds of mental states that are functionally related to one's imaginings (i.e., emotional responses, conative states, mental imagery, etc.), and so on.

${ }^{6}$ Some philosophers, e.g., Kind (2001), argue that imaginings must have an imagistic component; others (Walton 1990, 13; Van Leeuwen 2013, 222) disagree. My argument is neutral with respect to this debate. See also Arcangeli (2019b) for a recent discussion of the relation between mental images and sensory imagination. 
piano), and imagining being part of a certain scenario (e.g., imagining being on a battlefield) encompass more than just belief-like imaginings; the argument, however, focuses on belief-like imagining. In general, to achieve compatibility with the various accounts of belief-like imagining proposed in the literature, the minimum I will assume is that there is a kind of imagining, or a kind of imagining that is constrained in certain ways (see note 4), to which the following puzzle applies. ${ }^{7}$ Accordingly, my explanation of the puzzle will seek to reveal the specific features of this kind of imagining, or the specific constraints that render imagining subject to the puzzle. For convenience, I will describe the impossibility in question as an impossibility that applies to belief-like imagining in general.

The first step in explaining the puzzle will be to distinguish two ways in which one can imagine beliefs. These two ways of imagining beliefs are similar to the two ways in which we can have beliefs about beliefs.

${ }^{7}$ Defending a view on which belief-like imaginings are relatively unconstrained, Stock (2017) argues that "one can propositionally imagine that anything is the case, at least as long as one also imagines that there is some (good) explanation for it" (141). On Stock's view, my account should be interpreted as an explanation of why it is impossible to imagine a Moorean conjunction by virtue of imagining a good explanation for it. Since my starting point is the tension between imagining $p$ and imagining that one believes that not- $p$, the explanation for this tension can be framed in terms of different views of belieflike imagination, and specifically, views that impose minimal constraints on the scope of imaginative content. 


\section{Imagining Beliefs}

Beliefs can be thought of, and ascribed to a subject, in two different ways: from the thirdperson perspective or from the first-person perspective. The former involves ascribing a belief to a subject by invoking evidence regarding that subject's behavior (including facial expressions). For instance, upon perceiving, or having testimonial or other evidence that the subject is closing windows, saying 'it's pouring,' taking an umbrella from the umbrella stand, etc., we might ascribe to her the belief that it's raining. ${ }^{8} \mathrm{We}$ can also invoke this third-person evidential mode of belief-ascription in ascribing beliefs to ourselves. That is, evidence regarding our own conduct can also serve as evidence for the belief that we believe a certain proposition.

The second mode of belief-ascription pertains to self-ascription of beliefs. Though we sometimes self-ascribe a belief in the third-person manner just described (i.e., on the basis of behavioral evidence), self-ascription of beliefs is ordinarily carried out from the first-person perspective often associated with the notion of 'introspection.' In this paper, I will try to remain neutral regarding the question of whether self-ascription of beliefs is based on one's 'inner sense' (e.g., Lycan 1996) or on 'looking outward' for assurance that the content of the putative belief is true (Byrne 2005). Whether or not we have 'inner access,' or some other sort of privileged or unique access to our mental states, I will

${ }^{8}$ This description of third-person belief-ascription is largely theory-neutral. Specifically, it is compatible with both 'theory-theory' and simulation accounts of mindreading, since on both sorts of accounts, ascribing a belief from the third-person perspective is based on behavioral evidence. See Barlassina and Gordon (2017). 
assume that we usually ascribe beliefs to ourselves in a manner that differs from that in which we ascribe beliefs to others. Specifically, I will assume that there is a way to selfascribe beliefs without invoking behavioral evidence.

These two ways in which we ascribe beliefs reflect two ways in which we ordinarily think about beliefs. On the one hand, beliefs, being associated with certain behaviors, can be thought of as manifested in those behaviors. On the other, we can think of beliefs under a 'first-person' mode of presentation, namely, the mode of presentation under which they manifest themselves to the subject from the first-person perspective. This mode of presentation would presumably be unpacked differently by the different approaches to introspection. On inner-sense theories, there must be a specific mode of presentation under which a belief manifests itself to the subject's inner sense; hence, we can think of a belief, on these theories, under that mode. On 'looking-outward' theories (Byrne 2005), the first-person mode of presentation amounts to a belief's being 'transparent': the belief manifests itself in the subject's being in a position to reply, upon being asked whether she believes, e.g., that it's raining, by looking outward at the world, and seeing whether it is indeed raining. However we unpack the mode of presentation under which beliefs manifest themselves from the first-person perspective, my argument will focus on this mode.

The two ways in which real-world beliefs are ascribed to a subject, and, likewise, manifest themselves to us, also apply to imagined beliefs. On the one hand, we can imagine that a subject believes that it's raining by imagining her acting in ways associated with the belief that it's raining: we can imagine her closing windows, saying 'it's raining,' etc., and thus imagine that she believes that it's raining. We can also 
imagine ourselves having beliefs in this same manner, i.e., by imagining ourselves acting in the said ways. On the other hand, we can imagine ourselves having a belief from the first-person perspective, namely, without imagining ourselves acting in any particular way. Different theories of belief self-ascription would presumably give different accounts of how we imagine beliefs presented under the first-person mode. Inner-sense theories would argue that to imagine a belief under the first-person mode of presentation is to imagine the belief as it manifests itself to the subject's 'inner sense,' whereas 'lookingoutward' theories would argue that to imagine a 'first-person' belief is to imagine the belief as being 'transparent.' Whichever theory is correct, we can imagine ourselves having beliefs under the first-person mode of presentation, just as we can believe that we have beliefs under the first-person mode of presentation.

\section{The Puzzle}

The puzzle rests on the impossibility of imagining (in the belief-like sense) the conjunction ' $p$ and I believe that not- $p$ ' (' $p$ and I believe that not- $p$ ' is known as the 'commissive form' of Moore's paradox; my argument also applies to the 'omissive' form, i.e., ' $p$ and I do not believe that $p$.' For convenience, I will generally refer to the commissive form). This impossibility arises when four main conditions are fulfilled. The first condition is that the belief referred to in the second conjunct, i.e., 'I believe that not$p$,' is imagined under the first-person mode of presentation. Regardless of which account of first-person belief-manifestation is endorsed, the impossibility arises only if we try to imagine that we believe that not- $p$ under this mode of presentation. This condition is 
necessary, since it is possible to imagine the belief that not- $p$ by imagining ourselves, e.g., acting in ways associated with the belief that not- $p$, while also imagining that $p$. Compare: it is possible to believe that it's raining, while also believing, since we find ourselves acting in ways associated with the belief that it isn't raining, that we believe that it isn't raining.

Secondly, the impossibility in question arises, at least in many cases, only if the two conjuncts are imagined simultaneously. For under certain circumstances, it may not be problematic to imagine, e.g., that it's raining, and that one (first-person) believes that it isn't raining, if the two imaginings arise in succession. In fact, under certain circumstances, there is nothing problematic about imagining even overtly contradictory propositions successively. For instance, in reading a novel and imagining its content, we can imagine, as per the novel's implicit guidance, that person A is the villain, and subsequently, imagine that person B is the villain, not A. Such a shift from imagining one proposition to imagining a contradictory proposition may occur not only in reading fiction, but also in, e.g., daydreams and spontaneous imaginative projects with the said content. In such cases, imagining overtly contradictory propositions may nonetheless be impossible if the subject tries to imagine the contradictory propositions simultaneously.

Now if imagining explicitly contradictory propositions successively is possible, then, a fortiori, imagining that it's raining and subsequently imagining that one believes that it isn't raining, which (without further qualification) is not explicitly contradictory, is possible. For instance, we can imagine that it's raining, and subsequently imagine that, upon introspection, we discover that we believe that it isn't raining. In such a case, the imaginative project 'evolves' in a way that allows us to imagine the two conjuncts. 
Moreover, given such 'evolving' imaginings, we are likely to wind up imagining that we 'revise' the belief we discovered via introspection following our first imagining (i.e., the imagining that it's raining); conceivably, we could also wind up imagining that it isn't raining, as per the belief we imagined uncovering by introspection. In such cases, what I claim to nonetheless be impossible is to imagine that it's raining and that at the same time we (first-person) believe that it isn't raining. Note that the simultaneity condition need not apply in every case: in certain cases — specifically, where no 'belief revision' is imagined - the 'tension' between imagining the two conjuncts obtains even if the two conjuncts are imagined successively. To ensure that the impossibility in question ensues generally, I will simply assume that the two conjuncts are imagined simultaneously.

Note also that in addition to the condition that the imaginings arise simultaneously, the imagined events must be imagined as occurring simultaneously, and moreover: in the present. For it can easily be imagined that, e.g., it was raining, and I believed that it wasn't. (Compare: a subject can readily believe 'it was raining, and I believed that it wasn't raining.'). Similarly, a subject can imagine 'it will be raining tomorrow, and I will believe that it is not raining.' In short, the present-tense verbs in the imagined propositions are crucial, since the impossibility in question arises only if one tries to imagine the two events - i.e., that it is raining and that one believes that it isn't —as occurring in the present. Ordinarily, imagining different events as occurring in the present does not raise any particular problem. You can easily imagine, e.g., that you're lying on the sofa and that it's raining; that you're hungry and it's raining; that it's raining and you believe that it's indeed raining; etc. What you cannot represent in belief-like imagining 
(under the specified conditions) is that it's raining, and that you believe that it isn't raining.

Thirdly, the impossibility ensues only if, in imagining the two conjuncts, the imagining is 'directed' at the same fictional world. For we can imagine, simultaneously, that it's raining in one fictional world, and that we (first-person) believe that it isn't raining in a different fictional world. The notion of a fictional world is usually associated with the 'world' of a work of fiction, but also applicable to other sorts of imaginative projects (see Walton 1990; 2015, ch. 2): we refer to the 'world' of a game of makebelieve (e.g., in the aforementioned example, the world in which it is true that the nextdoor neighbor is a dragon), the 'world' of a daydream, etc. Even when imaginings arise spontaneously, we can, upon reflection, recognize the 'truths' of the world of our imaginative project, and the respects in which that world remained indeterminate.

Note that my account does not presuppose any specific theory of fictional worlds. For convenience, I will use Walton's characterization, taking a fictional world to be a "set of propositions" (1990, 66-67). ${ }^{9}$ That is, I will identify a fictional world with the set of

\footnotetext{
${ }^{9}$ More precisely, Walton characterizes fictional worlds as "sets of propositions-asindicated-by-a-given-work" (1990, 67). Two fictional worlds may thus be composed of the same set of propositions, yet differ because they are set forth in different works. Since Walton takes fictional worlds to be stipulated not only when engaging with fiction, but also in playing games of make-believe, daydreaming, etc. (Walton 1990, pp. 44-45), this characterization also applies to imaginative projects more generally: a fictional world is the set of propositions stipulated to be true in a given imaginative project. That is, a fictional world is associated with the mental activity - the imaginative project—in the
} 
propositions stipulated to be true in a given imaginative project. ${ }^{10}$ The relation between imaginings and stipulating fictional worlds will be further explained in $\S 4$. The point I'm making here is that it is impossible to imagine the conjunction only if our imagining is 'directed' at a single fictional world, that is, only if the two conjuncts are putatively assessed for truth in the same fictional world.

The fourth condition is that the imaginer must be sufficiently rational. This condition can be shown to be necessary by comparing the impossibility in question to Moorean impossibility. Famously, it is impossible for rational subjects to believe the conjunction ' $p$ and that I believe that not- $p$.' Although Moore's paradox applies primarily to assertions (i.e., it is impossible for a rational agent to assert ' $p$ and I believe that not-p'), the paradox also applies to the mental states that ground assertions, namely, beliefs. The point is that if a subject is irrational and can believe ' $p$ and I believe that not- $p$,' she can obviously also imagine this conjunction. A similar condition applies to the impossibility of imagining a contradiction. Although overt contradictions can hardly be imagined (Kind 2013, 151), if the imaginer is irrational to the effect that she can believe a contradiction, she can also imagine that contradiction. Much as the impossibility of imagining a contradiction ensues only if the imagining subject is sufficiently rational, the context of which it is set up. Hence it is also individuated by the relations between imaginings and other kinds of mental states that are part of the imaginative project (emotional responses, conative states, mental imagery, etc.).

${ }^{10}$ On this characterization, fictional worlds almost never overlap the real world, since they usually include propositions that are false simpliciter. Furthermore, unlike the real world, fictional worlds are usually highly indeterminate. 
impossibility of imagining ' $p$ and I believe that not- $p$ ' ensues only if the imaginer is sufficiently rational. (In $\S 4$, I explain the specific aspect that renders the imagining of Moorean conjunctions impossible).

Let me show how the impossibility ensues in a case where all the four conditions are clearly fulfilled. Consider an example adduced in Walton (1990, 37ff). Greg and Eric play a game of make-believe in which they take tree-stumps in the forest they're hiking through to be bears. The 'fictional world' of their game includes, among other propositions, propositions of the form 'there is a bear at spot $\mathrm{x}$ ' $-\mathrm{a}$ spot where there is a (real-world) stump. Suppose that Greg imagines, as per his belief that there is a stump in the bushes behind him, that there is a bear in the bushes. Greg then decides to imagine, in addition, that he believes that there isn 't a bear in the bushes, despite his real-world knowledge that there is a stump, and hence a fictional bear, at that spot. Let us take it for granted that Greg is rational, and thus cannot believe Moorean conjunctions (i.e., the fourth of the aforementioned conditions is met). Greg can fulfill his plan in three different ways (or combinations thereof).

First, Greg can simply stop imagining that there is a bear in the bushes, and proceed to imagine that he believes that there isn't a bear there. For imagining even overtly contradictory propositions in succession does not always pose a problem. (Note that shifting from one imagining to another at will does not, or not always, pose a problem, since imaginings, unlike beliefs, are uncommitted to truth, unconstrained by evidence, etc.). And of course, Greg can imagine a slightly-revised conjunction in which the verbs in the imagined propositions are not present-tense verbs: he can imagine, e.g., that there was a bear in the bushes, and he believed that there wasn't a bear there. Just like in 
Moore's puzzle, the impossibility does not arise if the events are not represented as occurring in the present.

Second, suppose that Greg wants to imagine, simultaneously, both 'there is a bear in the bushes,' and 'I believe that there isn't a bear in the bushes.' Greg can achieve this by temporarily directing the second conjunct at a different fictional world. That is, he can imagine the two scenarios - that there is a bear there, and that he believes that there isn't a bear there-as occurring in two different fictional worlds. In imagining that he believes that there is no bear there, Greg temporarily 'detaches' himself from the game's set-up, from what is taken to be true in its world, enabling him to imagine that belief.

Lastly, if Greg wants to imagine the conjunction while taking the conjuncts to be assessed for truth in the same fictional world - the world of the stumps-are-bears gamehe can imagine that there is a bear in the bushes, and (simultaneously) that he believes that there isn't a bear there, by imagining himself acting in ways associated with the belief that there isn't a bear there. Greg can even observe the stump and imagine a bear, but nonetheless act, as per his plan, like someone who believes that there are no bears around, that no bears have been sighted there, etc.; by virtue of these acts, he can simultaneously imagine that there's a bear in the bushes, and that he believes that there isn’t a bear there. As explained in $\S 2$, since it is possible to imagine oneself having a belief from the third-person perspective (i.e., by imagining one's actions), one can readily imagine that one believes, from the third-person perspective, that there isn't a bear in the bushes, while also imagining that there is a bear there.

In sum, given that Greg is rational, what Greg cannot do is imagine, simultaneously, both that there is a bear in the bushes, and that, in the same world (i.e., the game's 
fictional world), he believes, from the first-person perspective, that there isn't a bear there.

At first sight, it seems that imaginings parallel beliefs in this respect, as per Moore's paradox. Note that the said conditions apply to Moore's paradox too. In Moore's paradox, if the subject self-ascribes the belief that it isn't raining from the third-person perspective (i.e., by invoking behavioral evidence), believing the conjunction doesn't pose a problem even for rational subjects (Green and Williams 2007, 4ff; Fernández 2013, 123-124). For example, believing that she has her car keys, a subject may act in ways associated with the belief that she doesn't have her keys, and thus ascribe to herself, by virtue of that behavioral evidence, the belief that she doesn't have the keys, while still believing that she has them. Moreover, Moorean impossibility arises only if the rational subject tries to believe the two conjuncts simultaneously, and the conjuncts are formulated in the present tense. For she can obviously believe such a conjunction if the two conjuncts are formulated in the past- or future-tense, so as to express that she had, or will have, a false belief (see, e.g., Hintikka 1962, 65; Green and Williams 2007, 4). And furthermore, since Moore's puzzle applies to beliefs, the conjuncts are taken to be assessed for truth in the same world, i.e., the real world.

What is puzzling about instances of Moore's paradox is that although the conjunction is not contradictory, and could even be true, it cannot be believed (see, e.g., Adler and Armour-Garb, 2007; Fernández 2013, §4). Moore’s paradox has been accounted for in different ways. On one approach, an explanation of the paradox must show that to believe a Moorean conjunction is to be logically inconsistent. Since Moorean conjunctions themselves are not contradictory, the inconsistency is 
demonstrated by adding further premises. Specifically, in line with Hintikka's pioneering work on doxastic logic, and his claim that believing the Moorean conjunction is "indefensible" (1962, 67ff), it is argued that the irrationality of believing the conjunction — or, similarly, the impossibility of rationally believing the conjunctionfollows from certain axioms of rationality. Those who adopt this approach maintain that, modulo these axioms, believing ' $p$ and I believe that not- $p$ ' is impossible. ${ }^{11}$ A different approach to Moore's paradox eschews the invocation of axioms of doxastic logic. As Green and Williams (2007) point out, "if possible, an account of Moorean absurdity should not appeal to controversial principles of epistemic or doxastic logic" (11). ${ }^{12}$ That

${ }^{11}$ More specifically, taking 'Bp' to denote one's first-person belief that $p$, the idea is that, modulo the axioms of doxastic logic, $\mathrm{B}(\mathrm{p} \& \mathrm{~B}($ not-p)), as well as $\mathrm{B}(\mathrm{p} \&$ not- $\mathrm{Bp})$, are inconsistent. Regarding the omissive form, given that belief distributes over conjunction, $\mathrm{B}(\mathrm{p} \&$ not-Bp) entails $\mathrm{Bp}$ and $\mathrm{B}($ not-Bp). On the axiom according to which Bp entails $\mathrm{B}(\mathrm{Bp})$ (commonly referred to as axiom 4), this yields $\mathrm{B}(\mathrm{Bp})$ and $\mathrm{B}($ not-Bp), which violates another axiom of doxastic logic (axiom $D$ ), according to which a contradiction cannot be believed. The inconsistency of the commissive form is derived from another axiom (4c), according to which $\mathrm{B}(\mathrm{B}($ not-p)) entails $\mathrm{B}$ (not-p), which is inconsistent with the first conjunct, i.e., Bp; see, e.g., Rieger (2015, 217-218). Other logical analyses of the paradox have been suggested by Rieger (2015, 218ff), Van Benthem (2004), and others (Van Benthem discusses the paradox in the context of the paradox of the knower, analyzing it in terms of dynamic logic).

12 The claim that Moore's paradox does not involve a contradiction is occasionally made by those who generally do analyze epistemic paradoxes in terms of doxastic logic. E.g., 
is, although the Moorean absurdity arises from a failure of (theoretical or practical) rationality, invoking axioms that presumably apply to an ideal rational agent would not explain the failure. For instance, Coliva (2015) argues that the paradox does not arise from any inconsistency in the agent's beliefs: rather than analyzing the paradox in terms of inconsistencies between beliefs, Coliva analyzes it in terms of the impossibility of endorsing incompatible commitments, which would be "an impossible cognitive situation" (p. 189).

In this paper, I do not endorse any specific approach to explaining Moore's puzzle. For the puzzle addressed here is not Moore's puzzle. Rather, the puzzle is that, although belief-like imaginings are not beliefs, it is nonetheless impossible to imagine (in the belief-like sense) Moorean conjunctions. That is, whatever the explanation of Moore's puzzle, it presupposes a property of beliefs that is related to the fact that beliefs are truthcommitted. Imaginings, however, are not truth-committed, hence the puzzling aspect of Moore's paradox does not apply to them. The puzzle raised by imaginings is that, despite not being committed to truth, they cannot have Moorean conjunctions as their content.

Yalcin (2007) differentiates between doxastically-paradoxical conjunctions such as 'it is raining and it might not be raining,' and Moorean conjunctions, arguing that unlike those doxastically-paradoxical conjunctions, Moorean conjunctions are not contradictory, as their conjuncts do not "have incompatible truth-conditions" or "mutually entail each other's falsity" (984). 
To see that commitment to truth, or a certain property that follows from this commitment, ${ }^{13}$ is crucial to render beliefs subject to Moore's puzzle, compare beliefs to mental states that are not committed to truth, e.g., assuming, considering, speculating, entertaining a thought, etc. It is clearly possible to take any of these attitudes toward the conjunction 'it's raining, and I (first-person) believe that it isn't raining. ${ }^{, 14}$ We can easily entertain this conjunction in thought or assume it in a variety of contexts. For instance, in philosophical discussions about introspection, or about the differences between first- and third-person belief-ascription, we can assume, consider, or hypothesize that 'it's raining and I (first-person) believe that it isn't raining.' ${ }^{15}$ And obviously, when you read, and

${ }^{13}$ On the approach that analyzes Moore's puzzle in terms of doxastic logic (see note 11), the property of being committed to truth does not straightforwardly explain why beliefs are subject to the puzzle. On this approach, the specific property of beliefs that renders them subject to the puzzle is described by axiom $D$ (which indeed follows from the 'commitment to truth' feature), on which a contradiction cannot be believed.

${ }^{14}$ Note that, since we can obviously consider (assume, etc.) a contradiction, a fortiori we can consider (assume etc.) the conjunction ' $p$ and I consider (assume, etc.) that not- $p$.' In fact, we can also imagine ' $p$ and I imagine that not- $p$,' but in this case, the possibility of imagining this conjunction ensues since the real-world imagining and the imagined imagining are directed at two different fictional worlds.

15 That it is possible to consider (assume, hypothesize, etc.) Moorean conjunctions, but not to imagine them (in the sense discussed in this paper, and under the said conditions) is often implicit in various philosophical arguments. E.g., in discussing the 'brains in a vat' thought experiment, we can obviously consider the conjunction 'I'm a brain in a vat, 
understand, the proposition 'it's raining and I believe (from the first-person perspective) that it isn't raining,' you entertain this proposition in thought. Because entertaining such a conjunction in thought, assuming it, etc., do not involve a commitment to the conjunction's truth, taking such attitudes toward Moorean conjunctions is not problematic. The problem arises only with regard to believing Moorean conjunctions, since belief is truth-committed.

The puzzle in question arises from the fact that belief-like imaginings are like these 'weak' attitudes in not being committed to truth: imagining, like considering, assuming, etc., is truth-neutral, not truth-committed. As explained in $\S 1$, imaginings, despite being similar to beliefs both functionally and with respect to inferential mechanisms, do not track truth simpliciter. Yet despite their affinity with the 'weak' attitudes, imaginings cannot have Moorean conjunctions as their content. Hence the crucial question is why, given that we are relatively free to choose what to imagine, we can't imagine, under the said conditions, the conjunction ' $p$ and I believe that not-p.'

but I believe that I'm not.' Yet without further qualification, imagining this conjunction under the said conditions is impossible: we cannot imagine, e.g., that we are not really eating a delicious red apple, while simultaneously imagining that we believe, from the first-person perspective, that we are eating that apple. In trying to imagine the second conjunct, it seems that we must set aside our imagining of the first conjunct, 'detach' ourselves from it, and adopt a different perspective from which it is the case that we are eating the apple. 
To answer this question, we need to investigate why belief-like imaginings, despite being truth-neutral, cannot have Moorean conjunctions as their content. We must find a feature of belief-like imaginings that renders it impossible to imagine Moorean conjunctions.

\section{The Solution}

\subsection{Walton's Thesis}

It might be suggested that the feature of imaginings that explains the impossibility of imagining Moorean conjunctions follows from the fact that imaginings are committed, not to truth simpliciter, but rather to fictional truth. Consider the following passage from Walton:

Fictionality has turned out to be analogous to truth in some ways; the relation between fictionality and imagining parallels that between truth and belief. Imagining aims at the fictional as belief aims at the true. What is true is to be believed; what is fictional is to be imagined. $(1990,41)^{16}$

\footnotetext{
${ }^{16}$ Note that Walton uses 'fictionality' and 'fictional' to refer to fictional truth. Note also that, as explained in $\S 3$, the set of propositions stipulated to be true in an imaginative project constitutes a 'fictional world'; see Walton (1990, 66-67), and note 9 above.
} 
Walton's idea is that, when we engage in an imaginative project, our imaginings are 'directed' at a fictional world, seeking to represent 'facts' of that world, that is, to have the stipulated fictional truths as their content. In reading a novel, for instance, we are mandated to imagine the propositions that are taken to be true in the novel's world. In playing games of make-believe, we similarly seek to imagine that which is stipulated to be fictionally true. Recall Greg and Eric's game of make-believe, in which they take treestumps to be fictional bears (Walton 1990, 37ff). When Greg and Eric see something in the distance that they believe to be a stump, they immediately imagine, as per their game's rule that real-world stumps are fictional bears, that there is a bear at that spot. If, upon approaching, they discover that what looked like a stump from afar is just a boulder, their imaginings are altered accordingly, to reflect the fictional truth: they imagine that there isn't a bear at that spot. In this sense, much as beliefs track truth simpliciter, imaginings track fictional truth.

The impossibility of imagining Moorean conjunctions can be explained, so it might be argued, by invoking the commitment to imagine that which is fictionally true in one's imaginative project. Much as we cannot, in the truth-committed state of believing, accept the conjunction 'it's raining and I believe that it isn't raining' (under the said conditions), so we cannot accept that conjunction in the [fictional-truth]-committed state of imagining (under the said conditions). The idea is that whatever accounts for the impossibility of believing the Moorean conjunction also accounts for the impossibility of imagining it, since imaginings aim at the fictionally true just as beliefs aim at the true. ${ }^{17}$ When Greg,

${ }^{17}$ On the 'doxastic logic' approach (see note 11), formalizing the inconsistency that arises from Walton's thesis requires revising certain axioms. Assuming that, like beliefs, 
e.g., imagines that there is a bear at a certain spot, he cannot imagine, simultaneously, that he (first-person) believes that there isn't a bear at that spot. In this case, the impossibility of such an imagining clearly parallels the impossibility of the belief that

imagining propositions in a given imaginative project distributes over conjunction, IB(p \& B(not-p)) entails IB(p) and IB(B(not-p)) (where 'IB' denotes belief-like imagining). However, applying an 'imaginative' version of $4 c$ is problematic, since $\mathrm{IB}(\mathrm{B}($ not-p)) obviously does not entail B(not-p) (i.e., imagining a belief does not entail that the belief arises in the real world; moreover, even if it entailed this belief, we wouldn't arrive at the required contradiction). One way to derive a contradiction from $\operatorname{IB}(\mathrm{p})$ and $\operatorname{IB}(\mathrm{B}($ not- $\mathrm{P}))$ is to argue that, since the belief in question is imagined under the first-person mode of presentation, it is 'transparent' in the sense that $\operatorname{IB}(\mathrm{B}($ not-p)) entails $I B($ not-p). The idea is that if one imagines (first-person-) believing a proposition, one also imagines, due to the alleged transparency, that very proposition. We then get that IB(not-p) is inconsistent with $\operatorname{IB}(\mathrm{p})$, by an 'imaginative' version of axiom $D$. A different way to derive a contradiction is by accepting another thesis of Walton, i.e., that every imagining is de se (Walton 1990, §I.4), or specifically that imagining something involves "imagining (oneself) believing or knowing it" $(1990,214)$. On this thesis, the first conjunct, IB(p), entails $\operatorname{IB}(B(p))$. And since $B(p)$ and $B($ not-p) are inconsistent (i.e., as per the axiomatic analysis of Moore's paradox, i.e., regarding belief), their conjunction cannot be imagined. Note, however, that since I proceed to reject Walton's thesis, and argue that the impossibility in question ensues from a different kind of commitment, I will not develop or defend these ideas here. 
purportedly guides Greg's imagining, namely, Greg's belief about a real-world stump.

That is, much as Greg cannot believe, as per Moore's puzzle, 'there is a stump at a certain spot and I believe that there isn't a stump there,' he cannot imagine the corresponding conjunction in which 'stump' is replaced by 'bear.' In general, much as beliefs' commitment to truth renders it impossible to believe the conjunction, so the commitment of belief-like imaginings to fictional truth renders it impossible to imagine the conjunction. And since assuming, considering, entertaining a thought, etc., are committed neither to truth nor to fictional truth, assuming, considering, etc. Moorean conjunctions does not pose a problem.

This proposed solution, however, is flawed: the thesis that imaginings aim at fictional truth, that they seek to represent the propositions stipulated to be fictionally true, is incorrect. Walton (2015, ch. 2) himself acknowledges that his thesis, as initially proposed, raises various problems, adducing cases that, he maintains, demonstrate its deficiencies. In my view, the main problem is that we can imagine propositions we know to be fictional falsehoods without violating any alleged commitment to fictional truth. For were our imaginings committed to fictional truth as beliefs are committed to truth simpliciter, our epistemic practices vis-à-vis imagining would be like our epistemic practices vis-à-vis believing. But the former epistemic practices differ radically from the latter. Take the extent to which beliefs and imaginings are responsive to evidence. If we have evidence to the effect that a certain proposition is true, we are inclined to believe the proposition; absent evidence or beliefs to the contrary, we usually believe that which we have evidence for. Sometimes we do act irrationally, e.g., in self-deception. But we don't really seek, systematically and consciously, to adopt false beliefs. 
Imaginings, by contrast, are structured so as to allow us to take on erroneous perspectives, make discoveries, be surprised, etc., or more specifically: to imagine fictional falsehoods. No problem is raised, for instance, by reading a murder mystery a second time, and imagining, as per the work's implicit guidance, the fictional falsehood that the butler is the murderer, while knowing full well that it is true in the mystery's world that the UPS deliveryman is the murderer (Walton 2015, 24). Similarly, in playing the stumps-are-bears game, Greg might plan to imagine what it would be like to be surprised by a bear. Although Greg knows that there is a stump behind him, and therefore that it is fictionally true that there is a bear behind him, he can easily imagine, as per his plan, the fictional falsehood that there is no bear there. Greg's intention to experience a surprise-like feeling, by first imagining that fictional falsehood, and then imagining the fictional truth that there is a bear there, can be fulfilled without violating any putative commitment to fictional truth.

In short, in imagining, we can intentionally set aside our knowledge or beliefs about the fictional truth — just as we set aside our knowledge or belief that what we are imagining is false simpliciter. We do not resist imagining propositions we know to be fictional falsehoods, as we would were imaginings committed to fictional truth. Accepting that belief-like imaginings are not constrained by a commitment to fictional truth doesn't mean that they aren't constrained at all. As mentioned in $\S 1$, there are limits to what can be imagined; in this respect, imagining is not like assuming, considering, speculating, etc. To account for the impossibility of imagining Moorean conjunctions (under the said conditions), a specific sort of constraint on imagining must be introduced. 


\subsection{Walton's Thesis Revisited}

The first-pass solution can be revised. I suggest that, although imaginings are not committed to fictional truth as beliefs are committed to truth simpliciter, there is a sense in which they 'mimic' beliefs in this respect. Like the first-pass account, this suggestion accords with simulationist views of imagination (see, e.g., Kind 2013, §2; Balcerak Jackson 2016, §3); however, to solve the paradox, it analyzes the pertinent similarity between imagining and belief differently than the first-pass (Waltonian) solution. I contend that when we imagine, our real-world state of imagining is ipso facto taken to be a fictional state of (first-person) believing. For example, imagining that it's raining entails that one plays the fictional role of (first-person) believing that it's raining. There is, indeed, no real-world commitment to imagining that which is fictionally true. The actual, real-world commitment that applies to imagining is different: it is a commitment to a principle constitutive of imagining, the principle that imaginings ipso facto function, with respect to the imagined propositions, as fictional (first-person) beliefs. ${ }^{18}$

\footnotetext{
${ }^{18}$ As mentioned in $\$ 1$ and note 7 above, on certain accounts of imagining, to say that it is constitutive of belief-like imaginings that they are posited to be fictional first-person beliefs might be too strong. For on some accounts of imagining, imaginings are belieflike only in circumscribed respects, in specific contexts, or under specific constraints. To align with these views, my claim should be modified as follows: in the specific cases where imaginings are subject to the puzzle, they are subject to the puzzle because they function, or are constrained so as to function, as fictional first-person beliefs.
} 
This commitment is sufficiently flexible to enable imaginers to play not only the fictional role of believing truths, but also the fictional role of believing falsehoods. Specifically, we are free to disregard our (real-world) knowledge about the fictional world, and deliberately step into the fictional role of believing falsehoods; i.e., we are free to intentionally imagine fictional falsehoods. Since believing falsehoods is commonplace even for rational subjects, playing the fictional role of believing falsehoods does not pose a problem, hence imagining fictional falsehoods, or intending to do so, poses no problem. However, since we cannot believe Moorean conjunctions, we cannot take on the fictional role of believing Moorean conjunctions. This role is, indeed, impossible to fill, hence imagining Moorean conjunctions is impossible (under the said four conditions).

This calls for clarification. We obviously don't, or don't necessarily, imagine ourselves believing every proposition we imagine. In what sense, then, is it the case that imaginings are taken to be fictional (first-person) beliefs? To answer this question, a certain structural aspect of imaginative projects must be examined. As mentioned in $\S 3$, in addition to imaginings (as well as conative states, emotional responses, etc.), imaginative projects also comprise stipulations of fictional truths. There are many ways in which fictional truths can be set down: we can stipulate that a proposition is fictionally true by intending to imagine a fictional truth, or by devising rules or instructions to the effect that certain propositions are fictionally true; we can implicitly or explicitly take real-world objects or properties to be part of the fictional world, and thus (implicitly) set down that some of the propositions that are true simpliciter of those objects or properties are also true of those objects or properties in the fictional world; etc. Another salient way 
in which fictional truths are set down is by rules that take a real-world object (or a property, or an event) to be a different object (property; event) in the fictional world.

Greg and Eric, e.g., take tree-stumps to be fictional bears; similarly, a child might take a banana to be a fictional telephone, a wooden stick to be a fictional horse, or herself to be a hunter. Walton calls these real-world objects "props," and defines them as "generators of fictional truths" (Walton 1990, 37ff).

As Walton emphasizes, fictional truths are not always coextensive with propositions imagined by the imaginer: we don't necessarily imagine every proposition that is determined to be fictionally true; and we may, deliberately or not, imagine fictional falsehoods. Greg and Eric, e.g., might overlook a stump, or intentionally ignore it, in which case they would not imagine the fictional truth determined by the rule they devised, namely, that there's a bear at that spot. Moreover, they can imagine the fictional falsehood that there isn't a bear there. Fictional truths, in short, must not be identified with imagined propositions.

Indeed, the mental act or state of positing that a real-world object (property; event) is a different fictional object (property; event) should not be identified with imagining: prop-related stipulations (like stipulations of fictional truths in general) are one thing, imagining propositions is something else. Given that prop-related stipulations are irreducible to other mental acts or states, it would seem that they are a distinct element of imaginative projects. Of course, stipulations are generally made in a wide variety of contexts, not only in the context of imagining. But stipulations of fictional truths, specifically those that are made by props, have a specific function in imaginative projects: they regulate, or constrain, the manner in which the imaginer engages in a 
specific project, how the project evolves, etc., as Greg and Eric's game demonstrates. In this paper, I will not discuss this issue in detail. For the purposes of my argument here, all that needs to be accepted is that in an imaginative project, prop-related stipulations involve principles or rules. More specifically, in an imaginative project involving props, imaginers must follow the general rule that whatever the props stand for exists in the project's fictional world.

The insight that a fictional world is established by, among other things, prop-related stipulations is crucial for solving the puzzle in question. For just as real-world objects, properties and events can be taken to be different objects, properties and events in the fictional world, in particular, certain real-world mental states can be taken to be different mental states in the fictional world. One example is mental images, which are sometimes, if not always, taken to be fictional perceptual experiences. ${ }^{19}$ In imagining, e.g., that the

${ }^{19}$ This claim applies only to mental images that arise in the course of imagining, and not to those that arise in other contexts, e.g., in recollection. However, even in the context of imagining, some would dispute this claim. Arcangeli (2019b), e.g., argues that mental images are not a distinct kind of attitude, but rather a type of (sensory) content that is common to different attitudes (remembering, belief, desire, imagining). Hence it appears that, on Arcangeli's view, mental images (qua mental content) cannot serve as props. However, even on Arcangeli's view, real-world visual experiences (and, similarly, actions, desires, intentions) can serve as props. E.g., it is fictionally true of Greg and Eric's visual experience of a tree stump that it is a visual experience of a bear. In this vein, my claim is that imaginings themselves ipso facto serve as props: they are posited to be fictional first-person beliefs. 
sun is going down, we may conjure up a mental visual image of a sunset, and take this real-world mental image to be a fictional visual experience of a sunset. This fact may be reflected in our reports about our project. Being asked to describe our imaginative project, we may specify various fictional truths that follow from this 'swap,' e.g., that we observe the sun from a certain vantage point, that the sun has the specific visual properties represented by the (real-world) visual image, etc. Such reports follow from the fact that our mental images serve as props, and thus generate those fictional truths.

A similar 'swap' can be made vis-à-vis perceptual experiences. When Greg and Eric visually experience a tree-stump, they take their real-world visual experience of the stump to be a fictional visual experience of a bear. This 'swap' determines various fictional truths (e.g., that a bear is seen by Eric, that it is not seen by Greg, that it is observed by Eric from a certain perspective, etc.), which may be reflected also in the discourse between Greg and Eric. Greg may ask Eric whether he 'sees a bear' in the bushes; Eric may respond that he does indeed 'see a bear' there (i.e., as per his real-world visual experience of a tree-stump). Furthermore, Greg's and Eric's utterances are also stipulated to be different fictional utterances. Greg's real-world utterance is taken to be a fictional question about a bear, and Eric's utterance is taken to be a fictional assertion about a bear. Likewise, Greg's and Eric's real-world intentions or desires that generate those utterances (as well as other actions) are taken to be different fictional intentions or desires; e.g., Greg fictionally intends / desires, by virtue of his real-world intention / desire to convey that sentence, to learn whether there is a bear behind the bushes.

In general, many of Greg's and Eric's real-world actions, perceptual experiences, desires, intentions, and other mental states serve as props, i.e., as generators of fictional 
truths: they are stipulated to be various fictional mental states associated with bearhunting, thus rendering certain propositions fictionally true. Again, the imaginers need not imagine each proposition that follows from such 'swaps.' The fictional truths about their visual experiences, intentions, etc., are generated by such stipulations, and are not always represented in their evolving imaginings. Note that in addition to such particular cases where real-world mental states serve as props, there are also systematic accounts that invoke 'swaps' between mental states. Consider, e.g., Walton's account of pictorial experience, namely the experience we normally have in looking at a picture. On this account, pictorial experience (often called 'seeing-in') is partly-imaginative: in looking at a picture of, e.g., a horse, the picture's viewer takes her real-world visual experience of the picture's marked surface to be the fictional experience of seeing a horse (Walton 1990, ch. 8; cf. Chasid 2016). A similar kind of 'swap' is invoked by Walton in his account of emotional responses to fiction. Walton argues that 'fear,' 'pity,' 'hate,' and other emotional states that arise in response to imagining are not ordinary fear, pity, and hate. Rather, they are quasi-emotions (quasi-fear, quasi-pity, quasi-hate). In addition to their being real-world states generated by imaginings, these quasi-emotions are taken by the imaginer to be fictional emotions: the imaginer's real-world quasi-fear, quasi-pity, and quasi-hate are taken to be fictional fear, fictional pity, and fictional hate, respectively. For instance, when Charles responds to his imagining that he is chased by a monster by experiencing quasi-fear (which is, again, not fear), this real-world state of quasi-fear serves as a prop: taken to be a fictional fear, it generates the fictional truth that Charles is afraid of the monster (Walton 1990, $\$ 7.1$ and $§ 7,2 ; 2015$, ch. 14). 
Following this line of thought, I contend that it is constitutive of imaginative projects that our (real-world) states of belief-like imagining are taken, probably implicitly and without much awareness, to be fictional first-person beliefs: in imagining a proposition, we ipso facto take ourselves to (first-person) believe that proposition in the fictional world. This constraint on imagining commits us to playing the role of fictional believers, i.e., believers of fictional truths or fictional falsehoods; it doesn't commit us to imagining only fictional truths (as Walton's thesis implies). Specifically, we can intentionally imagine fictional falsehoods: we can structure our imaginative project in such a way that we imagine propositions from the perspective of a believer who is ignorant of certain evidence, is misled into believing falsehoods, etc., as happens in rereading a murder mystery, in Greg's plan to imagine being surprised by a bear, and in similar cases.

There are, however, propositions that, much as they cannot be (first-person) believed, cannot be taken to be (first-person) believed in the fictional world, and hence cannot be imagined. Whatever the reason a subject cannot (first-person) believe the conjunction 'it's raining and I believe that it isn't raining,' she likewise cannot play the role of (first-person) believing that conjunction. ${ }^{20}$ In other words, the impossibility in

${ }^{20}$ On the said formalistic approach, this should be analyzed in terms of a commitment to follow the principle that imaginings are posited to be fictional (first-person) beliefs. This idea can be expressed by assuming that an 'ideal' imaginer must also imagine the fictionally-true proposition that follows from this principle, namely, she must imagine $\mathrm{B}(\mathrm{p} \& \mathrm{~B}($ not $-\mathrm{p}))$. However, since $\mathrm{B}(\mathrm{p} \& \mathrm{~B}($ not $-\mathrm{p}))$ is contradictory (according to the standard analysis of Moore's paradox in terms of doxastic logic; see note 11), it cannot be imagined (as per the impossibility of imagining a contradiction). 
question is the impossibility of following a constitutive rule, namely, the rule that ensues from the fact that belief-like imaginings serve as props. In imagining, we can take on the role of false believers, but qua rational subjects, taking on the role of believers vis-à-vis Moorean conjunctions is impossible. Hence we cannot imagine Moorean conjunctions.

Note that following the rule according to which one's real-world state of imagining is taken to be a fictional state of believing does not presuppose any specific description of a fictional believer; that is, without additional stipulations, the fictional (first-person) believer has no determinate identity. Indeed, the fictional believer's indeterminacy reflects the descriptively-lean manner in which beliefs are ascribed from the first-person perspective. ${ }^{21}$ We may not be aware that, in imagining, we play the role of first-person believers, and it is obviously not necessary that we imagine ourselves believing anything. Yet playing this role is integral to belief-like imagining, and is reflected in the manner in which our imaginings unfold (see note 18).

Since it is constitutive of belief-like imaginings that they are posited to be fictional (first-person) beliefs, we cannot imagine Moorean conjunctions. We can entertain Moorean conjunctions in thought, consider them, etc., since these attitudes are not bound by a constraint such as that which applies in the case of imaginings, i.e., they are not stipulated, in the sense specified above, to be fictional beliefs. The impossibility of imagining Moorean conjunctions also differs from the impossibility of believing Moorean conjunctions, for unlike beliefs, imaginings are not committed to truth (nor are they committed to fictional truth, as Walton asserted). Rather, the impossibility of imagining Moorean conjunctions is the impossibility of following a principle constitutive of

\footnotetext{
${ }^{21}$ On the first-person perspective in the context of imagining, see Nichols (2008).
} 
imagining, namely, that the imaginer plays the role of fictional (first-person) believer visà-vis fictional truths. ${ }^{22}$

As I noted above, my proposed explanation of the impossibility of imagining ' $p$ and I believe that not-p' accords with simulationist accounts of imagination: it invokes a feature that explains how imaginings 'simulate' beliefs specifically with respect to having Moorean conjunctions as their contents. Indeed, since Walton's thesis that imagining aims at the fictional truth as belief aims at truth (which can also be deemed a simulationist thesis) is problematic, ascribing the proposed feature to imagining shows that the impossibility of imagining Moorean conjunctions is not anomalous. Despite the

${ }^{22}$ In this paper, I defend the claim that imaginings are ipso facto posited to be first-person beliefs by arguing that it provides a cogent and plausible explanation of the impossibility in question. I have presented other arguments for this claim elsewhere (see Chasid 2020; forthcoming). Let me sketch the contours of one such argument here. Consider the following example. In reading a work of fiction and imagining that $\mathrm{A}$ is the villain (as the work's first chapters implicitly direct us to do), and then shifting to imagine that B, not A, is the villain (as per the final chapter's guidance), we ascribe a sense of 'error' to our first imagining, we feel a surprise-like or discovery-like feeling, etc. Such reactions arise even if we read the work a second time, i.e., while knowing the pertinent fictional truths. I argue that these reactions-i.e., ascribing 'error,' feeling 'surprised,' etc.—show that we posit a fictional doxastic point of view vis-à-vis the propositions we imagine. More generally, our responses to imagining demonstrate that, when we imagine, we posit ourselves to be fictional believers vis-à-vis what we imagine, although we do not necessarily imagine ourselves believing anything. 
complexity it ascribes to imagining, my account does not rest on any element of imaginative projects that has not been acknowledged in the literature. Although props and their logic (qua generators of fictional truths) have been examined chiefly by Walton (1990), to my knowledge, no one has denied that prop-related stipulations-e.g., in taking a banana to be a fictional telephone, a stick to be a fictional sword, or oneself to be a fictional hunter-play an important role in imaginative projects. The way in which props function specifically when they are mental states might explain other phenomena associated with imagination, as the aforementioned examples seem to indicate. This issue obviously requires a separate discussion.

\section{Conclusion}

I started by showing that, under certain conditions, it is impossible to imagine (in the belief-like sense of 'imagining') the proposition ' $p$ and I believe that not- $p$.' I then adduced a puzzle: since belief-like imagining—like assuming, entertaining in thought, etc.- -is not committed to truth, why is it that we nonetheless cannot imagine Moorean conjunctions, whereas we can assume, entertain in thought, and consider them? Despite the unequivocal difference between imagining and believing vis-à-vis truth-commitment, with respect to Moorean conjunctions, imagining seems to be like believing, and not like the mental attitudes of assuming, entertaining in thought, speculating, etc.

To solve the puzzle, I first adduced Walton's thesis that imaginings parallel beliefs in 'aiming' at the truths pertinent to them: imaginings are committed to fictional truth just as beliefs are committed to truth simpliciter. Showing that Walton's thesis is problematic, I 
proposed, instead, that imaginings mimic beliefs in that they are posited to be fictional (first-person) beliefs. In imagining a proposition, we ipso facto take ourselves to play the role of (first-person) believing that proposition in the fictional world. Hence since it is impossible to believe Moorean conjunctions, it is also impossible to imagine such conjunctions, that is, to play the role of believing such conjunctions.

To explain the sense in which, in imagining, we posit ourselves to be fictional believers, I invoked Walton's notion of props. I argued that much as we stipulate that real-world objects or properties are different objects or properties in the fictional world, we can also stipulate that real-world mental states are different mental states in the fictional world. This is the sense in which the real-world state of imagining is ipso facto stipulated to be a fictional state of (first-person) believing.

I concluded that the impossibility of imagining Moorean conjunctions does not ensue from the alleged commitment to imagining the fictional truth-a commitment expressed in Walton's thesis $(1990,41)$ that "imagining aims at the fictional as belief aims at the truth." Rather, it is the impossibility of acting in accordance with a principle constitutive of belief-like imagining, namely, the principle that our perspective vis-à-vis the content of our imaginings is the fictional first-person perspective of a believer.

Acknowledgments: I am grateful to those who commented on this paper and helped sharpen the argument. In particular, I'd like to thank Anna Ichino, Peter LanglandHassan, Julia Langkau, Nessa Olshansky-Ashtar, Alik Pelman, Eric Peterson, and Assaf Weksler for their input. An earlier version of this paper was presented at the 2019 SSPP annual meeting, where I received valuable feedback. I also want to thank two anonymous 
referees, and the ROPP Editor, for their insightful comments. This research was supported by the Israel Science Foundation (grant No. 939/16).

\section{References}

Adler, Jonathan E. and Armour-Garb, Bradley (2007). "Moore's Paradox and the Transparency of Belief," in Mitchell S. Green and John N. Williams (eds.), Moore's Paradox: New Essays on Belief, Rationality, and the First Person. Oxford: Oxford UP, $147-162$.

Arcangeli, Margherita (2019a). Supposition and the Imaginative Realm. New York: Routledge.

Arcangeli, Margherita (2019b). "The Two Faces of Mental Imagery," Philosophy and Phenomenological Research (Early view)

Balcerak Jackson, Magdalena (2016). “On the Epistemic Value of Imagining, Supposing, and Conceiving," in Amy Kind \& Peter Kung (eds.), Knowledge Through Imagination. Oxford: Oxford UP, 41-60.

Barlassina, Luca and Gordon, Robert (2017). "Folk Psychology as Mental Simulation," The Stanford Encyclopedia of Philosophy, Edward N. Zalta (ed.), URL = <https://plato.stanford.edu/archives/sum2017/entries/folkpsych-simulation/>.

Byrne, Alex (2005). “Introspection,” Philosophical Topics 33 (1): 79-104.

Chasid, Alon (2016). "Imaginatively-Colored Perception: Walton on Pictorial Experience," Southern Journal of Philosophy 54 (1): 27-47. 
Chasid, Alon (2020). "Imagining in Response to Fiction: Unpacking the Infrastructure," Philosophical Explorations 23, 31-48.

Chasid, Alon (forthcoming). "Belief-like Imagining and Correctness," American Philosophical Quarterly.

Coliva, Annalisa (2015). “How to Commit Moore's Paradox," Journal of Philosophy 112 (4):169-192.

Currie, Gregory and Ravenscroft, Ian (2002). Recreative Minds: Imagination in Philosophy and Psychology. Oxford: Oxford UP.

Doggett, Tyler and Egan, Andy (2007). "Wanting Things You Don’t Want," Philosophers' Imprint 7 (9): 1-17.

Doggett, Tyler and Egan, Andy (2012). "How We Feel About Terrible, Non-existent Mafiosi," Philosophy and Phenomenological Research 84 (2): 277-306.

Fernández, Jordi (2013). Transparent Minds: A Study of Self-Knowledge. Oxford: Oxford UP.

Gendler, Tamar (2003). "On the Relation between Pretense and Belief," in Matthew Kieran and Dominic Lopes (eds.), Imagination, Philosophy, and the Arts. London: Routledge, 125-41.

Green, Mitchell S., and Williams, John N., (eds.) (2007). Moore's Paradox: New Essays on Belief, Rationality, and the First Person. Oxford UP.

Hintikka, Jaakko (1962). Knowledge and Belief. Ithaca: Cornell UP. Ichino, Anna (2019). "Imagination and Belief in Action," Philosophia: 1-18. Kind, Amy (2001). "Putting the Image Back in Imagination," Philosophy and Phenomenological Research 62: 85-109. 
Kind, Amy (2013). "The Heterogeneity of the Imagination," Erkenntnis 78 (1):141-59.

Kind, Amy (ed.) (2016). "Introduction: Exploring Imagination," in Amy Kind (ed.), Routledge Handbook of Philosophy of Imagination. New York: Routledge, 1-11.

Langland-Hassan, Peter (2012). "Pretense, Imagination, and Belief: the Single Attitude Theory," Philosophical Studies 159 (2): 155-179.

Liao, Shen-yi and Doggett, Tyler (2014). "The Imagination Box," Journal of Philosophy 111 (5): 259-275.

Liao, Shen-yi and Gendler, Tamar (2020), "Imagination," The Stanford Encyclopedia of Philosophy, Edward N. Zalta (ed.), URL = <https://plato.stanford.edu/archives/win2018/entries/imagination/>.

Lycan, William (1996). Consciousness and Experience. Cambridge MA: MIT Press. Nichols, Shaun (2004), "Imagining and Believing: The Promise of a Single Code," Journal of Aesthetics and Art Criticism 62 (2): 129-139.

Nichols, Shaun (2006). "Introduction," in Shaun Nichols (ed.), The Architecture of the Imagination, New York: Oxford UP, 1-16.

Nichols, Shaun (2008). “Imagination and the I," Mind \& Language 23(5): 518-535.

Nichols, Shaun and Stich, Stephen (2003). Mindreading: An Integrated Account of Pretence, Self-Awareness, and Understanding of Other Minds, Oxford: Oxford UP. Rieger, Adam (2015). "Moore's Paradox, Introspection and Doxastic Logic," Thought: A Journal of Philosophy 4 (4):215-227.

Stock, Kathleen (2017). Only Imagine: Fiction, Interpretation and Imagination. Oxford: Oxford UP. 
Tuna, Emine Hande (2020). "Imaginative Resistance," The Stanford Encyclopedia of Philosophy, Edward N. Zalta (ed.), URL = <https://plato.stanford.edu/archives/sum2020/entries/imaginative-resistance/>.

Van Benthem, Johan (2004). "What One may Come to Know," Analysis 64 (2):95-105.

Van Leeuwen, Neil (2011). "Imagination is Where the Action is," Journal of Philosophy 108 (2): 55-77.

Van Leeuwen, Neil (2013). “The Meanings of 'Imagine' Part I: Constructive Imagination," Philosophy Compass 8 (3): 220-230.

Walton, Kendall (1990). Mimesis as Make-Believe, Cambridge MA: Harvard UP.

Walton, Kendall (2015). In Other Shoes: Music, Metaphor, Empathy, Existence. New York: Oxford UP.

Weinberg, Jonathan and Meskin, Aaron (2006), "Puzzling Over the Imagination: Philosophical Problems, Architectural Solutions," in S. Nichols (ed.). The Architecture of the Imagination. New York: Oxford UP, pp. 175-202.

Yalcin, Seth (2007). “Epistemic Modals,” Mind 116 (464):983-1026. 